\title{
Simulation of Granular Organic Fertilizer Application by Centrifugal Spreader
}

\author{
Raimonda Zinkevičienè ${ }^{1, *}$, Eglè Jotautienè ${ }^{1}$, Antanas Juostas ${ }^{1}$, Antonio Comparetti ${ }^{2}$ (C) \\ and Edvardas Vaiciukevičius ${ }^{1}$ \\ 1 Institute of Agricultural Engineering and Safety, Agriculture Academy, Vytautas Magnus University, \\ Studentu 15, LT-53362 Akademija, Lithuania; egle.jotautiene@vdu.lt (E.J.); antanas.juostas@vdu.lt (A.J.); \\ edvardas.vaiciukevicius@vdu.lt (E.V.) \\ 2 Department of Agricultural, Food and Forest Sciences, University of Palermo, Viale delle Scienze, Building 4, \\ 90128 Palermo, Italy; antonio.comparetti@unipa.it \\ * Correspondence: raimonda.zinkeviciene@vdu.lt; Tel.: +370-614-38071
}

check for updates

Citation: Zinkevičienè, R.; Jotautienè, E.; Juostas, A.; Comparetti, A.; Vaiciukevičius, E. Simulation of Granular Organic Fertilizer Application by Centrifugal Spreader. Agronomy 2021, 11, 247. https:// doi.org/10.3390/agronomy11020247

Academic Editors: Egidijus Šarauskis and Vilma Naujokiene

Received: 16 January 2021

Accepted: 26 January 2021

Published: 29 January 2021

Publisher's Note: MDPI stays neutral with regard to jurisdictional claims in published maps and institutional affiliations.

Copyright: (c) 2021 by the authors. Licensee MDPI, Basel, Switzerland. This article is an open access article distributed under the terms and conditions of the Creative Commons Attribution (CC BY) license (https:// creativecommons.org/licenses/by/ $4.0 /)$.

\begin{abstract}
There is no specialized equipment designed to spread granular cylindrical organic fertilizer in the soil. There are also no rational recommendations available on how to spread this type of fertilizer. Mineral fertilizer spreaders are most often used for spreading granulated organic fertilizer. However, these fertilizers are significantly different from mineral fertilizers. Due to these differences, organic granular fertilizers often are spread unevenly, and the fertilizer does not reach the required working width. Furthermore, the rate of spreading is not accurate, and the fertilizer is often crushed too much. The objective of this research is to develop a simulation model for granular organic fertilizer applications with a centrifugal spreader in EDEM (extended distinct element method) software. It is possible to develop a numerical model that corresponds to a real spreader, and to determine the key physical-mechanical parameters for the application of granular organic fertilizer. This model can also be used for evaluating the transverse uniformity of the fertilizer in the field (along the trajectory normal to the machine). The results of this research show that the distance traveled by the fertilizer granules partially depends on the particle size, initial speed, type of fertilizer and the parameters of the spinning discs of the spreader.
\end{abstract}

Keywords: biofertilizer; extended distinct element method; manure; spreading simulation model; spatially variable rate fertilizer application

\section{Introduction}

Crop yield is affected by soil quality, which is quantified by its structure (micro- and macro-porosity), soil cone penetrometer resistance (index of soil compaction), arable layer depth, texture, $\mathrm{pH}$, nutrient, water and organic matter content. Therefore, in order to improve soil quality, it is important to perform the most efficient crop operations, e.g., fertilization. Livestock farms in the European Union produce around 1400 million tons of manure every year [1]. In Lithuanian agriculture, the main organic waste is manure and straw. Organic farms can only use biofertilizers. Differently from mineral fertilizers, biofertilizers can not only increase the soil nutrient content but also improve its structure, and therefore, its soil quality [2]. Therefore, the need for organic fertilizers is constantly increasing throughout the EU. Due to the aforementioned large amount of manure produced in EU livestock farms [3], they can contribute not only to the improvement of soil quality and, therefore, the increase in crop yield, but also to the reduction in the waste to be disposed of. A promising method of manure management is granulation, i.e., the processing of this raw material into organic fertilizers. Granular organic fertilizers are easy to handle, transport, store and spread on the soil. In fact, the optimal quantity of soil nutrients dissolves faster in ground water and is more easily absorbed by plants $[3,4]$. 
The agricultural machines most popular in Europe for applying granular organic fertilizers on the soil surface are centrifugal spreaders, because of their low price, easy maintenance and large working width, i.e., 18-50 m [5]. They include a hopper with two discharge openings (shutter slides) at the bottom, and two discs, one spinning clockwise and the other counter-clockwise [5]. Even if these spreaders have been mainly used for spatially uniform rate fertilizer distribution, they are also used for spatially variable rate application, according to the principles of precision agriculture [6-9]. In fact, the measurement of soil parameters allows for generating soil maps which, together with the yield map, would generally show more accurately the demand for macronutrients, such as nitrogen, phosphorous and potassium. In response to growing concerns about the environment and farmers' desires to reduce the crop input costs, and therefore increase their profits, researchers have concentrated on spatially variable rate fertilizer application. When the fertilizer is applied according to site-specific requirements, its leaching into ground and surface water is minimized, while a significant amount of the input of this expensive crop is saved. Moreover, the under- and over-dosage of fertilizers have been reported to cause yield losses [10]. When using spreaders for applying granular organic fertilizers, instead of mineral ones, it is important to improve and develop fast, cheap and reliable application methods [10].

In order to increase the efficiency of fertilizer use, the research must be focused on the technical specifications of centrifugal spreaders that are provided with variable speed spinning discs, as well as on the transverse uniformity of fertilizer application (along the trajectory normal to the machine). The dynamics of the spreading of fertilizer particles are influenced by the fixed and variable technical specifications of the spreader, e.g., the rotation speed and position of spinning discs, the blade angle of discs, the size of discharge opening (shutter slide), the spot where each particle falls down onto the spinning disc, the discharge flow rate, the machine's forward speed and the working width. The landing point of a particle on the soil depends on the trajectory of the particle itself, which is thrown by the spinning disc into the air. As several accidental factors contribute to changes in particle trajectory during the spreading process [11], a simulation model of the centrifugal spreader, taking into account the fertilizer's properties, is needed. In fact, an experimental investigation on fertilizer spreading takes a long time and is expensive. Therefore, in order to save both time and cost, modeling could be used for analyzing the dynamics of fertilizer spreading.

Olieslagers et al. [12,13] described a simulation model of the spinning discs of a fertilizer spreader. This model relies on the laws of physics to track the motion of fertilizer particles as they fall on the spinning disc of the spreader, are thrown to the air and land on the soil. By computing a high number of particle trajectories for different initial conditions, a pattern of spreading on the soil can be statistically determined. The simulation of the spreader action allows for investigating a large range of parameters affecting the motion of the particles, i.e., the properties of the particles themselves and the machine parameters to be set up. Thus, the simulation model could be integrated into the setting-up and control system of the fertilizer spreader. In addition, it could also be useful for the design and optimization of the spreader, reducing the number of prototypes produced and the number of setting-up tests to be carried out.

The spreading model described by Olieslagers et al. [12,13], based on the formula developed by Olieslagers, Ramon, Delcourt and Bashford, as well as some additional analyses making it more general, considers the motion of the particle from the time it touches the spinning disc coming from the hopper to the moment it lands on the soil.

Further developments have focused more on the motion of the particle thrown in the air by the spinning disc. Hofstee and Huisman [14] investigated the influence of various physical-mechanical properties of fertilizer (particle size, friction coefficient, restitution coefficient, aerodynamic resistance and particle strength) on the particle's motion from the hopper to the spinning disc and through the air. 
The majority of theoretical research performed by other scientists has been focused on the trajectory of fertilizer particles. By using the discrete element method (DEM), it is possible to better simulate the spreading process and to obtain more accurate results over large areas of fertilizer application $[15,16]$. The increasing use of organic fertilizers and centrifugal spreaders determines the need for modeling the fertilizer application, in order to achieve the most uniform transverse distribution.

The extended distinct element method presented in this paper can be used to optimize the spreading of granular organic cylindrical fertilizers. Simulation helps to improve the spreading process of the fertilizer spreader in a much cheaper and faster way. Based on the developed model, the results are interpreted in detail. Further and more detailed assessment and research on the changes in the parameters of organic fertilizers would ensure the high-quality spreading of these fertilizers.

\section{Materials and Methods}

Granular fertilizers made of organic material, i.e., poultry manure composted in cylindrical pellets, are used in this research. The properties of these pellets, such as dry matter, particle density, granular diameter, granular length and friction coefficient, were estimated by experimental research [17] in Lithuania, in a laboratory based at the Institute of Agricultural Engineering and Safety of Agriculture Academy of Vytautas Magnus University. Cylindrical-shaped granular organic fertilizer particles were manually selected for spreading simulation. Ten granules were randomly picked to obtain the average value and error of the physical and biometric parameters of the granules [17]. Numerous studies have described in detail the methods of studying the physical-mechanical properties of fertilizer granules $[11,16]$. Based on the physical-mechanical properties presented in Table 1 of the granules, a 3D model of granular organic fertilizers was developed. These parameters were used to model the spreading of granular fertilizers in the EDEM environment.

Table 1. Main physical-mechanical parameters of granular organic fertilizers.

\begin{tabular}{ccc}
\hline Parameter & Fertilizer I & Fertilizer II \\
\hline Dry matter, $\%$ & 90 & 88 \\
Particle density, $\mathrm{kg} \mathrm{m}^{-3}$ & 650 & 700 \\
Granule diameter, $\mathrm{mm}$ & $4 \pm 0.12$ & $6 \pm 0.36$ \\
Granule length, mm & $6 \pm 0.8$ & $11 \pm 1.1$ \\
Friction coefficient of pellets & 0.45 & 0.47 \\
Aerodynamic coefficient of pellets & 0.91 & 0.82 \\
\hline
\end{tabular}

Examples of particles of granular organic fertilizers, based on poultry manure, are presented in Figure 1.

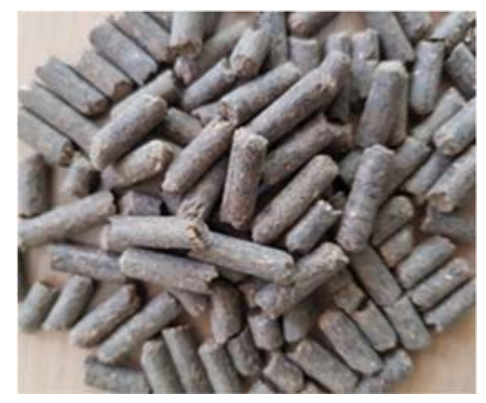

(a)

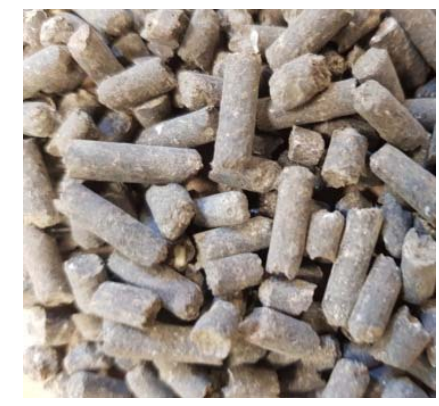

(b)

Figure 1. Granular organic particles based on poultry manure: (a) granules with a diameter of $6 \mathrm{~mm}$; (b) granules with a diameter of $4 \mathrm{~mm}$.

After the physical and mechanical parameters were set in the EDEM software to design the pellet model, the force applied to the pellet itself moving at the appropriate 
speed was calculated, and the coefficient of aerodynamic resistance was determined. A 3D model of granular organic fertilizer particles was developed in the EDEM software [18]. The particle was modeled as two spheres, according to biometric parameters and so as to fit the cylindrical form as much as possible. The model and the natural granule are shown in Figure 2.
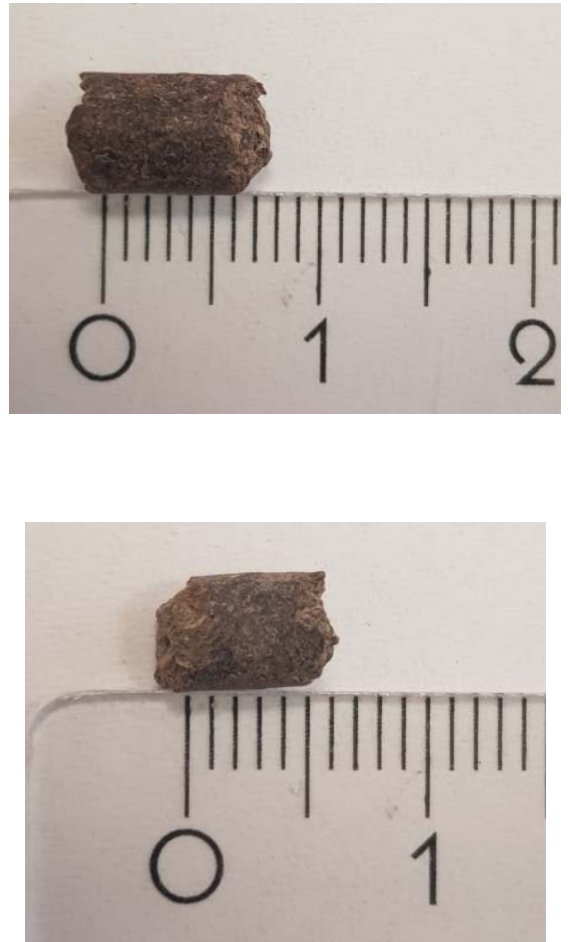

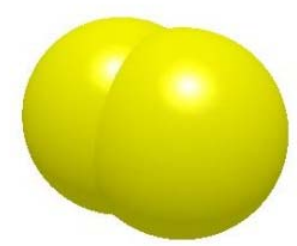

$k_{x}^{2}$

(b) (a)

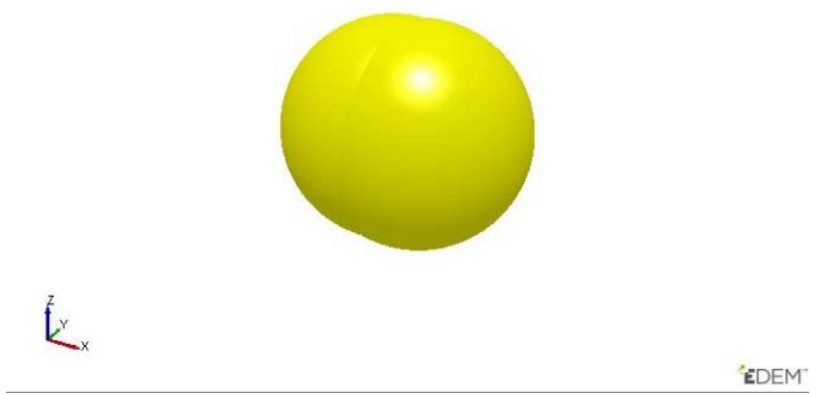

$k_{x}^{x}$

EDEM-

EDEM

Figure 2. The natural granule photo (left side) and the model of the particle (right side) are shown: (a) Fertilizer I; (b) Fertilizer II.

The physical-mechanical parameters of granular organic fertilizers were assigned to the pellet model (Table 2). In order to create the motion of a similarly naturally distributed fertilizer flow, each particle in the simulated fertilizer model can be multiplied $\mathrm{n}$ times.

Table 2. Parameters of fertilizer spreader Amazone ZA-M used to create spreader and rotating discs model.

\begin{tabular}{cc}
\hline Parameter & Value \\
\hline Working width & $14 \mathrm{~m}$ \\
Spinning discs height (distance between disc and ground) & $0.9 \mathrm{~m}$ \\
Distance between the discs & $105 \mathrm{~m}$ \\
Discs' diameter & $60 \mathrm{~cm}$ \\
Spreader height & $0.9 \mathrm{~m}$ \\
\hline
\end{tabular}

To ensure the reproducibility of the research, extended distinct element method (EDEM) software was used to model the centrifugal fertilizer spreader. The parameters of an Amazone ZA-M centrifugal fertilizer spreader were selected for the simulation model, and these parameters are shown in Table 1 [19].

A working width of $14 \mathrm{~m}$ was set up for the tested fertilizer. The application rate of granular organic fertilizers was selected according to the manufacturer's recommendations for such a centrifugal fertilizer spreader [19]. The simulation with EDEM software required spreader parameters such as discharge opening (shutter slide) size, spinning disc rotation speed and height (distance between disc and ground), and the blade angle of the discs. In 
order to perform the tests, based on the above-mentioned centrifugal fertilizer spreader, a spreading model with the following technical parameters was developed: dual disc; distance between the discs $-105 \mathrm{~cm}$; disc diameter $-60 \mathrm{~cm}$; length of the blade $-32 \mathrm{~cm}$ with non-rotating angle and $36 \mathrm{~cm}$ with a $5^{\circ}$ rotation, respectively. The spreader reaches a height of $0.9 \mathrm{~m}$ and a speed of $2.2 \mathrm{~m} \mathrm{~s}^{-1}\left(7.92 \mathrm{~km} \mathrm{~h}^{-1}\right)$. The disc rotation speed is about $65 \mathrm{rad} \mathrm{s}^{-1}\left(621 \mathrm{~min}^{-1}\right)$, with a fully open discharge opening. The inclination angle of the spinning discs was set to zero. This model was developed using a 3D modeling tool. The real spinning discs and their model developed in the EDEM software are presented in Figure 3.

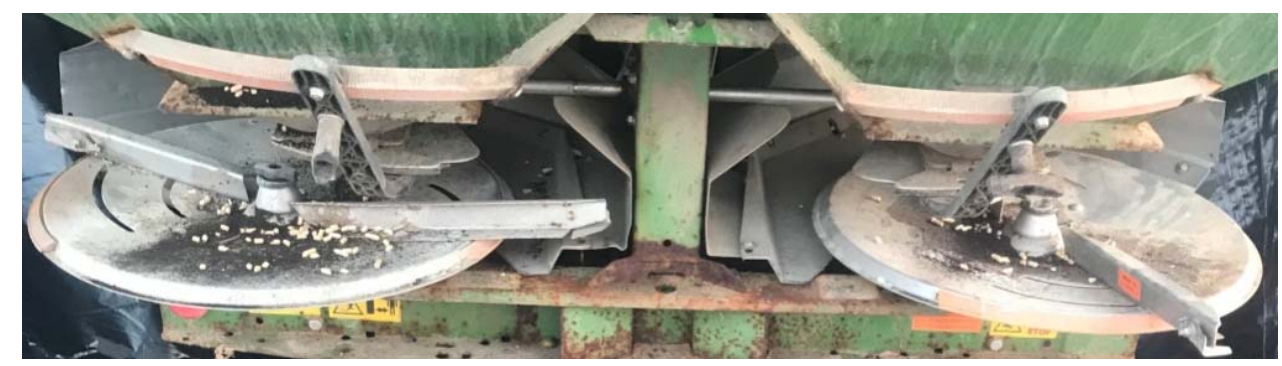

(a)

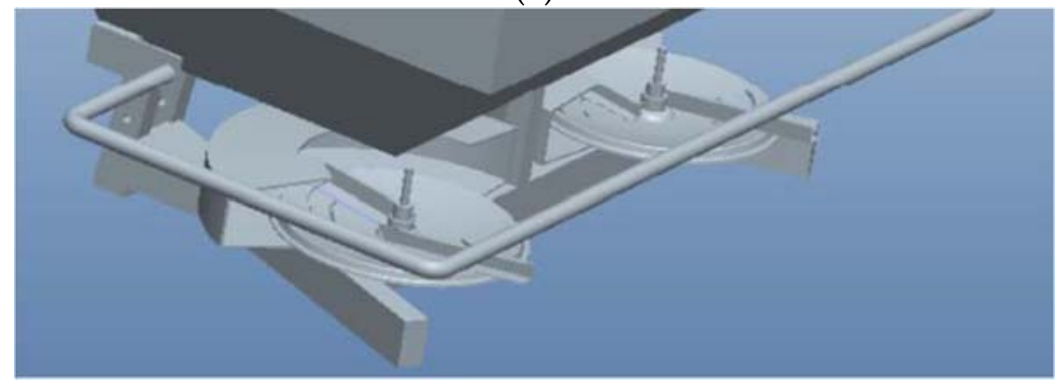

(b)

Figure 3. Spinning discs: (a) real ones; (b) their model developed in EDEM software.

The solid works flow software was used to create the dual disc fertilizer spreader model. The model was saved in the Initial Graphics Specification format (.igs) and imported into the EDEM (v4.0.0) software. The parameters of the fertilizer spreader selected for modeling in the EDEM software are presented in Table 3.

Table 3. Parameters of fertilizer spreader selected for modeling.

\begin{tabular}{cc}
\hline Parameter & Value \\
\hline Centrifugal spreader disc rotation speed, $\mathrm{min}^{-1}$ & $450 / 600$ \\
Fertilizer discharge flow rate, $\mathrm{g} \mathrm{s}^{-1}$ & $200 / 400$ \\
Simulation time, $\mathrm{s}$ & 6 \\
\hline
\end{tabular}

The parameters affecting the trajectory of particle motion were selected for the investigation of fertilizer application values, based on both kinematic and dynamic analyses. The distance of the particles falling in the direction of the inclined plane at any throwing angle can be described by the equation of motion of each particle based on Newton's Second Law of Motion. All the acting forces (contact, gravity, drive) and the mass of the particles are evaluated by Newton's equations of motion [14,15]. The type of material, the coefficient of friction of the fertilizer and the main environmental characteristics were continuously recorded to ensure the accuracy of the DEM simulation. The environmental parameters affecting particle motion (wind speed $-7 \mathrm{~m} / \mathrm{s}$; humidity $-70 \%$; temperature $-16{ }^{\circ} \mathrm{C}$ ) were assigned to the simulation model. The model was implemented by simulating the fertilizer spreader moving on the field. The default values of Hertz-Mindlin (no slip) with relative 
velocity-dependent (RVD) rolling friction contact (i.e., EDEM software) were used for the simulation analysis. The EDEM software estimates the rolling friction, which depends on the relative rotational speed of the pair of elements. A model simulating rolling friction in EDEM software was applied to the contact surfaces at constant torque. The torque (Equation (1)) was influenced by the velocity of the two exposed particles (particle $i$ and particle j) $[20,21]$.

The torque can be expressed by $[21,22]$

$$
\vec{\tau}_{i}=-\mu_{r} F_{n} R^{*} \hat{\omega}_{r e l}
$$

where $\mu_{r}$ is the coefficient of rolling friction, $R^{*}$ is the equivalent radius of two elements in contact, $\omega_{\text {rel }}$ is the vector of relative rotational velocity, $F_{n}$ is the normal force. The value $\vec{\tau}_{j}$ is equal to $\vec{\tau}_{i}$ and is acting at opposite direction.

As the torque depends on the velocity $\omega_{\text {rel }}$ of two particles, this velocity has to be expressed in the second form. Particle to particle and particle to geometry interaction are represented in formula (3), where $\hat{n}$ evaluates the vector from the particle to the point of contact [21]:

$$
\begin{gathered}
\hat{\omega}_{r e l}=\hat{n}_{i j} \times \vec{v}_{t_{i j}} /\left|v_{t_{i j}}\right| \\
\vec{v}_{t_{i j}=}\left\{\begin{array}{c}
-\frac{1}{2}\left(\vec{\omega}_{i}+\vec{\omega}_{j}\right) \times \vec{r}_{i j} \\
-R_{i} \vec{\omega}_{i} \times \hat{n}_{i j}
\end{array}\right.
\end{gathered}
$$

Here $\hat{n}_{i j}$ is a unit vector pointing from particle $i$ to the point of contact, and $r_{i j}$ is the radius of the particle.

It is important to understand the process by which the elements of model development were incorporated into the EDEM program. First of all, as previously described, we created a particle model in the program. Then the spreading equipment developed in the SolidWorks environment and the operating parameters of this equipment were added to create the virtual particle spreading model. When the equipment is connected in the program, a virtual soil surface is created. Figure 4 shows an image of what a field and a spreader model look like in an EDEM environment.

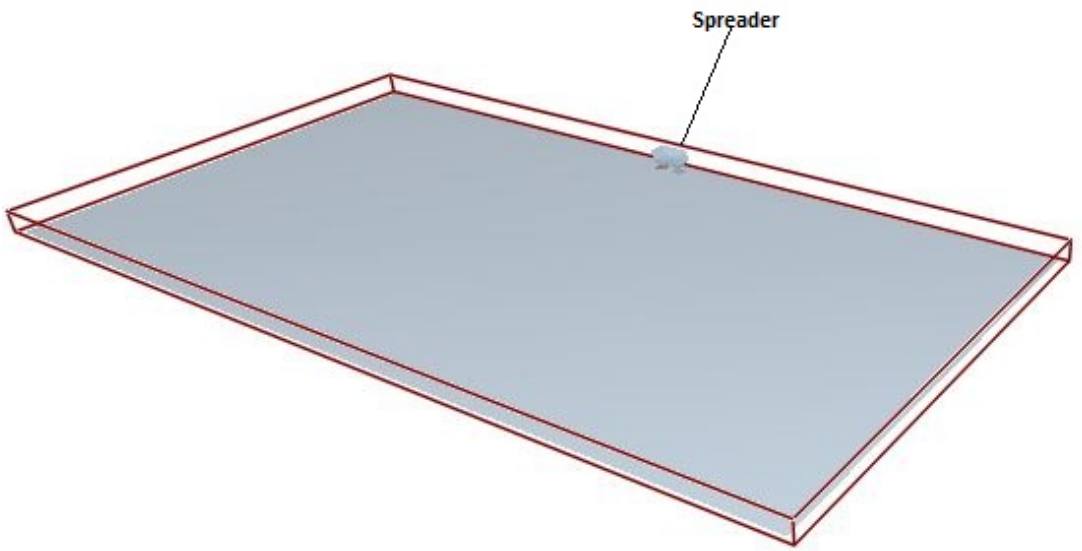

Figure 4. Soil surface and AMAZONE spreader model in the EDEM environment.

The simulation time was chosen so that the results of the calculations would not change during the tests in intervals of $6 \mathrm{~s}$ or more. In order to increase the modeling accuracy, the values of simulation corresponded to the actual within-field movement of the centrifugal fertilizer spreader.

The simulation in EDEM was repeated three times. It was possible to simulate real fertilizer application as the spreader works on the field. The DEM model of the dual 
disc centrifugal spreader was imported into the EDEM software for simulating fertilizer application on the field.

\section{Results and Discussion}

After the creation of all elements were created, their interactions were set: particle to particle and particle to disk. The simulation of the model was started after all these interactions were set. The particle to particle bond with EDEM material properties were used for the initial setup and evaluation. The properties set in the program are given in Table 4.

Table 4. Properties used in EDEM for particle-particle connection evaluation.

\begin{tabular}{cc}
\hline Parameter & Value \\
\hline Poisson's Ratio (v) & 0.25 \\
Solids density $(\rho)$ & $650 / 700 \mathrm{~kg} / \mathrm{m}^{3}$ \\
Young's Modulus (E) & $3.0 \mathrm{~Pa}$ \\
Coefficient of Restitution & 0.5 \\
Coefficient of static friction & $0.45 / 0.47$ \\
Coefficient of Rolling friction & 0.01 \\
\hline
\end{tabular}

Also to evaluate the connection between particle to particle it was set to evaluate HertzMindlin (no slip) model. This model is based on Poisson's ratio (v). In this study parameters presented in Table 3 were evaluated by the experimental researches of the fertilizer.

To evaluate the particle to geometry the same properties were used as the interactions between particle to particle were evaluated. In this case particle and the disc of the spreader connection was also evaluated by Hertz-Mindlin (no slip) model. Only in this case equipment material was not bulk material as in particle-to particle contact evaluation. As discs are made of steel properties were added with different values to ensure the evaluation of particle to geometry. Additional properties for particle to geometry evaluation can be seen in Table 5.

Table 5. Additional parameters for particle-geometry evaluation.

\begin{tabular}{cc}
\hline Parameter & Value \\
\hline Poisson's ratio & 0.5 \\
Solids density $(\rho)$ & $8000 \mathrm{~kg} / \mathrm{m}^{3}$ \\
Shear Modulus $(G)$ & $7.5 \mathrm{~Pa}$ \\
\hline
\end{tabular}

All the calculations provided by the EDEM software are based on these properties.

The results obtained during virtual spreading were processed and described by evaluating the average distance travelled by the fertilizer particles, i.e., from the spinning disc to the soil, was estimated based on the rotation speed of the spinning discs during the tests. Figure 5 shows the average distance travelled by particles of the fertilizers I and II when the discharge flow rate was $200 \mathrm{~g} \mathrm{~s}^{-1}$.

The highest average distance traveled by the fertilizer particles was $14.69 \mathrm{~m}$, when the rotation speed of the spinning discs was $450 \mathrm{~min}^{-1}$. However, the shortest average distance traveled by the fertilizer particles was $11.94 \mathrm{~m}$, when the rotation speed of the spinning discs was $600 \mathrm{~min}^{-1}$.

Figure 6 shows the average distance traveled by the particles of fertilizers I and II when the discharge flow rate was $400 \mathrm{~g} \mathrm{~s}^{-1}$. 


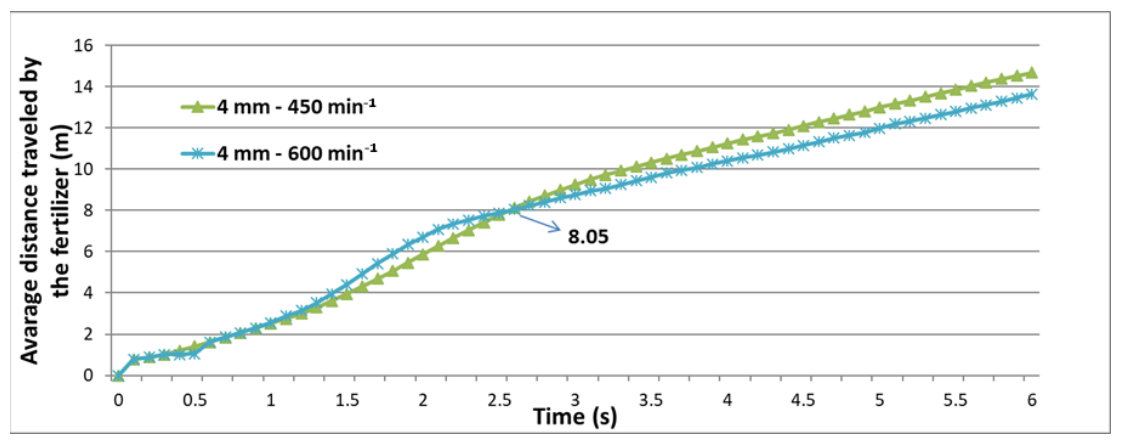

(a)

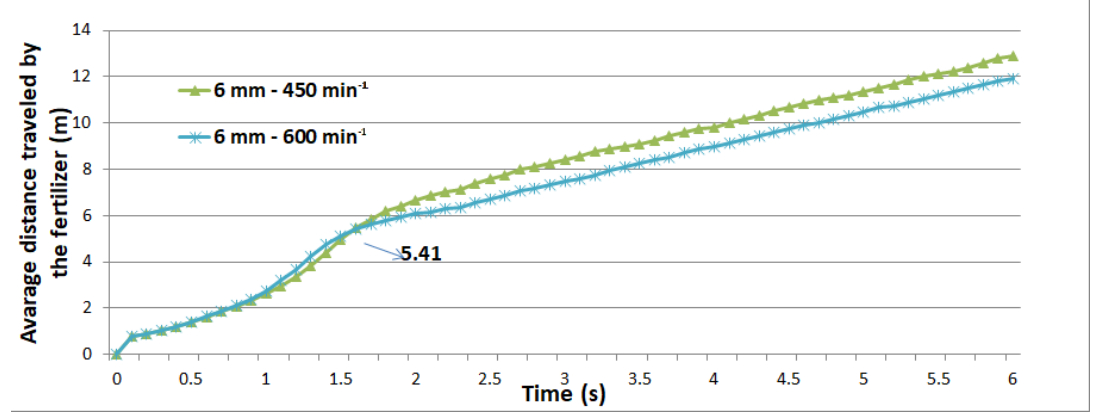

(b)

Figure 5. Average distance traveled by the particles of fertilizer I (a) and fertilizer II (b), when the discharge flow rate was $200 \mathrm{~g} \mathrm{~s}^{-1}$.

The highest average distance traveled by the fertilizer particles was $15.03 \mathrm{~m}$ when the discharge flow rate was $400 \mathrm{~g} \mathrm{~s}^{-1}$ and the disc rotation speed was $450 \mathrm{~min}^{-1}$. The shortest distance traveled by the fertilizer particles was $11.82 \mathrm{~m}$ when the discharge flow rate was $400 \mathrm{~g} \mathrm{~s}^{-1}$ and the disc rotation speed was $600 \mathrm{~min}^{-1}$.

During $6 \mathrm{~s}$ of simulation, the results of the ballistic model showed that the highest average distance traveled by the granular organic fertilizer did not influence the discharge flow rate of the fertilizer at a rotation speed of $450 \mathrm{~min}^{-1}$. The average distance traveled by the granular fertilizer was always shortest when the disc rotation speed was $600 \mathrm{~min}^{-1}$ within $6 \mathrm{~s}$ of simulation, regardless of the discharge flow rate.

The simulation results showed that disc rotation speeds of 450 and $600 \mathrm{~min}^{-1}$ and discharge flow rates of 200 and $400 \mathrm{~g} \mathrm{~s}^{-1}$ did not affect the average distance traveled by the granular fertilizers. In fact, the average distance traveled by the fertilizer granules depends directly on the rotation time of the disc: the longer the granule moves on the disc, the greater the distance traveled by the granule itself. The obtained results showed that the particles of higher mass traveled further when the aerodynamic resistance was 1.1 times lower than that of the lower mass granules. Similar results were obtained by other researchers [12].

The average velocities of the particles of granular organic fertilizers I and II were estimated during the simulation, based on the disc rotation speed at discharge flow rates of 200 (Figure 7) and $400 \mathrm{~g} \mathrm{~s}^{-1}$ (Figure 8). Similar results were obtained when applying the fertilizer at the $200 \mathrm{~g} \mathrm{~s}^{-1}$ discharge flow rate and with both disc rotation speeds selected450 and $600 \mathrm{~min}^{-1}$. When the average granule velocity reached $3-3.9 \mathrm{~m} \mathrm{~s}^{-1}$, the disc rotation speed reached its highest value and then the particle velocity began to decrease slightly. The highest granule velocity of $12.41 \mathrm{~m} \mathrm{~s}^{-1}$ was observed when the disc rotation speed was $450 \mathrm{~min}^{-1}$ for fertilizers II. The lowest granule velocity was recorded at the disc rotation speed of $450 \mathrm{~min}^{-1}$, while the highest granule velocity, i.e., $6.23 \mathrm{~m} \mathrm{~s}^{-1}$, was obtained at the disc rotation speed of $600 \mathrm{~min}^{-1}$. 


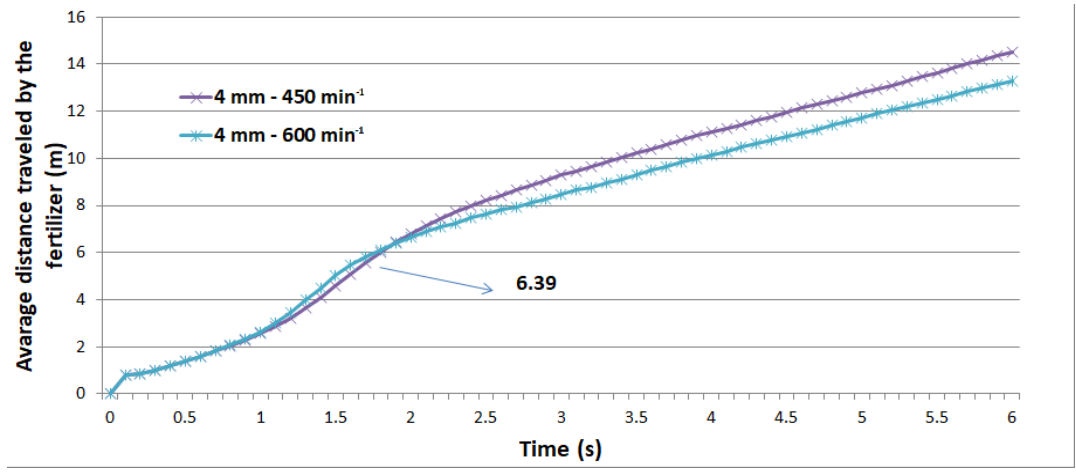

(a)

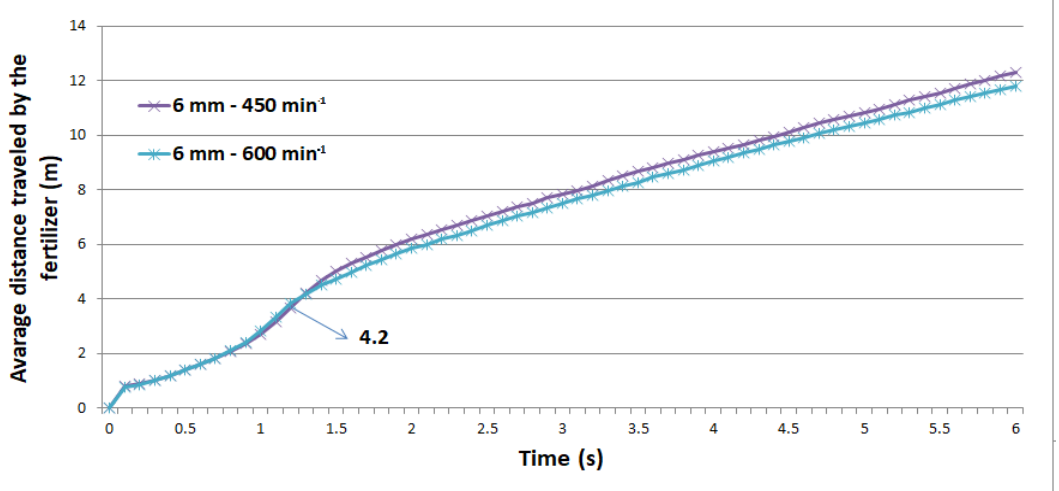

(b)

Figure 6. Average distance traveled by the particles of fertilizer I (a) and fertilizer II (b), when the discharge flow rate was $400 \mathrm{~g} \mathrm{~s}^{-1}$.

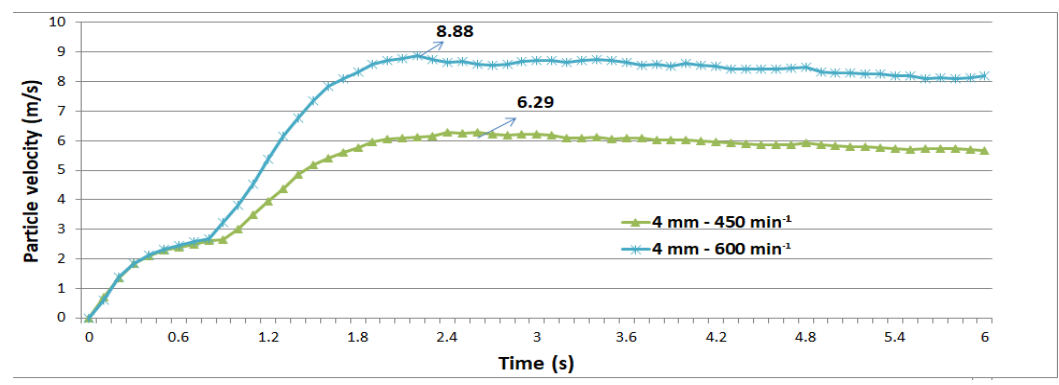

(a)

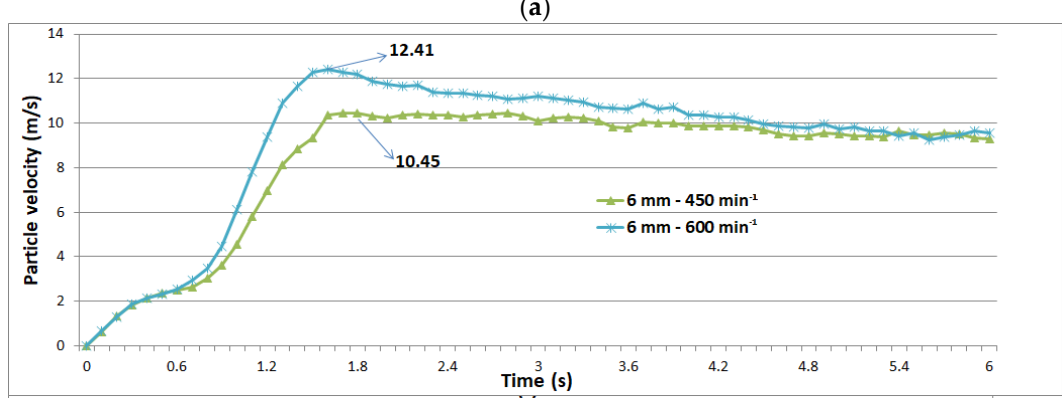

(b)

Figure 7. Average velocity of the particles of fertilizer I (a) and fertilizer II (b) when the discharge flow rate was $200 \mathrm{~g} \mathrm{~s}^{-1}$. 


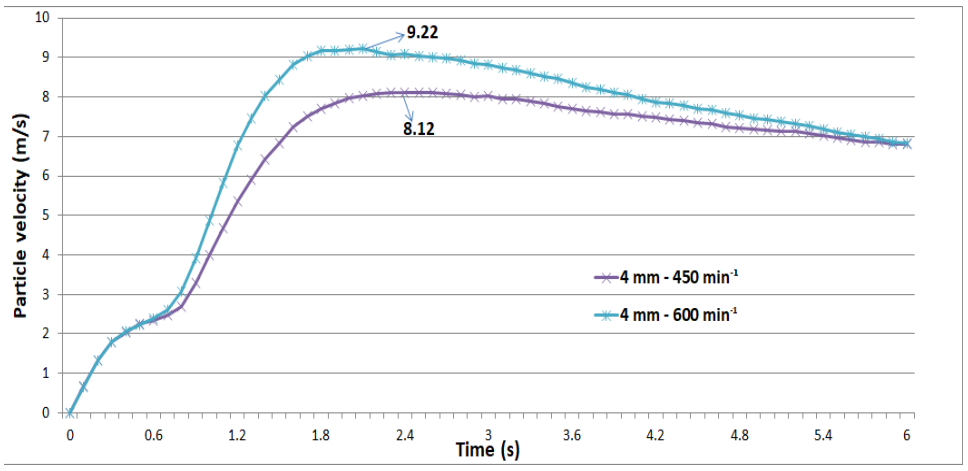

(a)

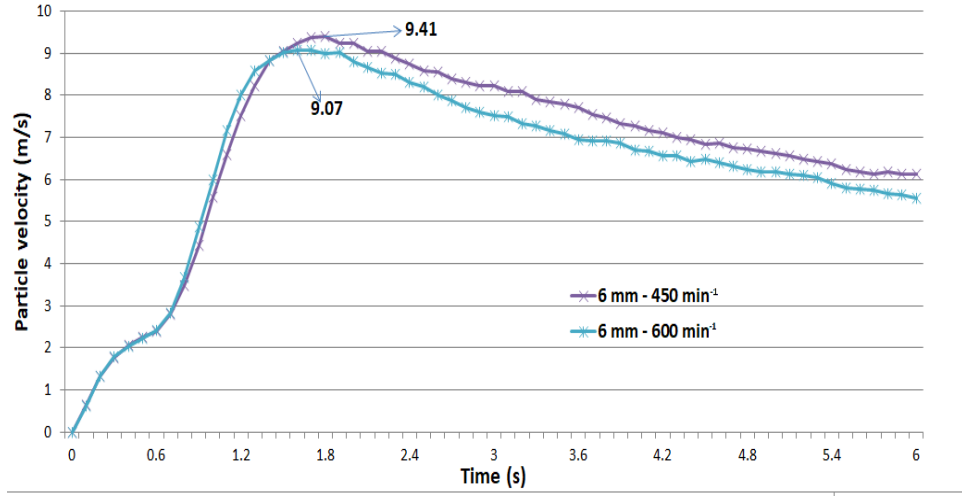

(b)

Figure 8. Average velocity of particles of the fertilizer I (a) and fertilizer II (b) when the discharge flow rate was $400 \mathrm{~g} \mathrm{~s}^{-1}$.

As is shown in Figure 9, the highest velocity of granular fertilizer was recorded at the higher disc rotation speed $\left(600 \mathrm{~min}^{-1}\right)$. The highest granule velocity was reached at the disc rotation speed of $450 \mathrm{~min}^{-1}$, with fertilizer II (granule diameter of $6 \mathrm{~mm}$ ). The highest granule velocity was reached during the simulation time of $1.9 \mathrm{~s}$. The highest granule velocity, i.e., $10.25-10.82 \mathrm{~m} \mathrm{~s}^{-1}$, was recorded at the disc rotation speed of $450 \mathrm{~min}^{-1}$.

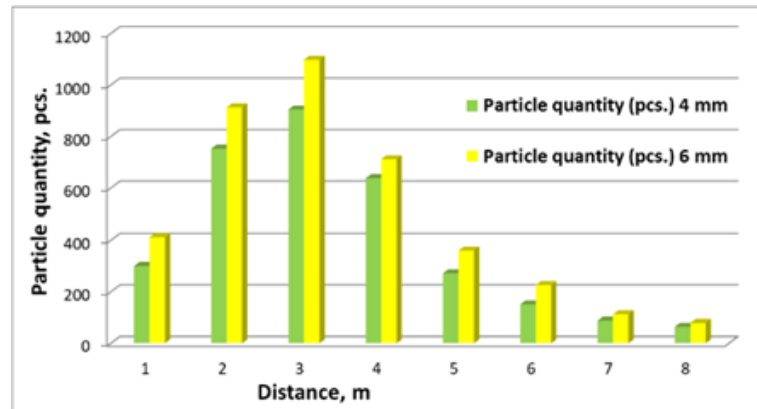

(a)

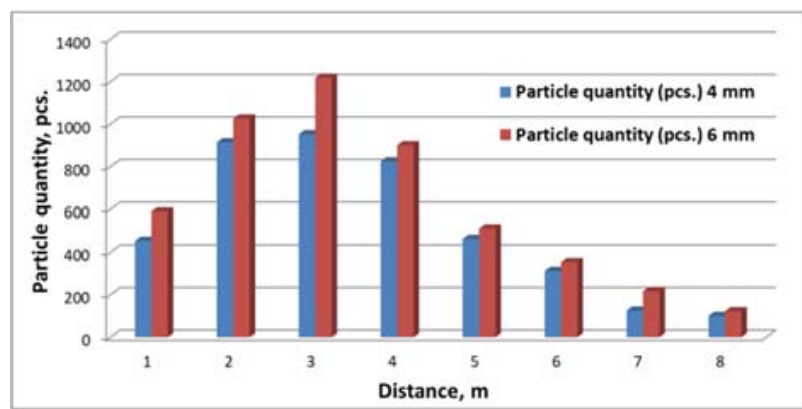

(b)

Figure 9. Spreading of fertilizer granules obtained at a disc rotation speed of $450 \mathrm{~min}^{-1}$ : (a) normal discharge flow rate of $200 \mathrm{~g} \mathrm{~s}^{-1}$; (b) normal discharge flow rate of $400 \mathrm{~g} \mathrm{~s}^{-1}$.

The lowest granule velocity was recorded at the disc rotation speed of $450 \mathrm{~min}^{-1}$ with fertilizer I (granule diameter of $4 \mathrm{~mm}$ ). In fact, the highest granule velocity at this disc rotation speed was $6.15 \mathrm{~m} \mathrm{~s}^{-1}$. According to the simulation results, the dispersion rate of the granular organic fertilizer particles was constant over time. The speed of the fertilizer flying in the air varied from 10.52 to $11.79 \mathrm{~m} \mathrm{~s}^{-1}$.

The simulation of fertilizer granule spreading was carried out, and the results are presented in Figures 8 and 9. 
The obtained results showed that the mass of the granular organic fertilizer particles was evenly spread over the simulation time. However, this is more relevant at a theoretical level, as it is difficult to implement in practice.

As is shown in Figure 9, when analyzing the spreading of both 4 and $6 \mathrm{~mm}$ diameter particles, the distribution of fertilizer granules at the disc rotation speed of $400 \mathrm{~min}^{-1}$ was lower than the normal (Gaussian $\mathrm{g}^{2}$ ) curve. The mean scatter of the data in Figure 9a at a discharge flow rate of $200 \mathrm{~g} \mathrm{~s}^{-1}$ is -1.42 for particles with a diameter of $4 \mathrm{~mm}$, and -1.12 for particles with a diameter of $6 \mathrm{~mm}$. This means that $\mathrm{g}^{2}<0$ and suggests that the standard deviation of the data is larger than the normal curve. The higher quantity of particles is spread at a distance of about 3-6 m from the disc, and strongly decreases between $0-2$ and 7-8 $\mathrm{m}$. This indicates that the particle distribution of granular organic fertilizers is not uniform. Similar results are observed when analyzing the data presented in Figure $7 \mathrm{~b}$ at the discharge flow rate of $400 \mathrm{~g} \mathrm{~s}^{-1}$. A $4 \mathrm{~mm}$ diameter particle $\mathrm{g}^{2}$ is -1.81 and a $6 \mathrm{~mm}$ diameter particle is -1.36 . This means that $\mathrm{g}^{2}<0$ and suggests that the standard deviation of the data is larger than the normal curve. Higher amounts of particles are distributed at a distance of about 3-6 $\mathrm{m}$ from the disc, and this strongly decreases between 0-2 and 7-8 $\mathrm{m}$. This indicates that the particle distribution of granular organic fertilizers is not uniform. However, the $\mathrm{g}^{2}$ also suggests that the granules of manure-based organic fertilizers are more evenly distributed at a particle diameter of $6 \mathrm{~mm}$.

Similar results are observed when analyzing the data shown in Figure $9 \mathrm{~b}$. For particles of $4 \mathrm{~mm}$ diameter, the $\mathrm{g}^{2}$ is 0.86 , and for particles of $6 \mathrm{~mm}$ diameter the $\mathrm{g}^{2}$ is 1.35 . This means that $\mathrm{g}^{2}<0$, and suggests that the standard deviation of the data is greater than the normal curve. The higher quantity of particles is spread at a distance of about 3-6 $\mathrm{m}$ from the disc, and strongly decreases between 0-2 and 7-8 $\mathrm{m}$. This indicates that the particle distribution of granular organic fertilizers is not uniform. However, the $\mathrm{g}^{2}$ also suggests that the particles of manure-based organic fertilizers are more evenly distributed when the granules have a $4 \mathrm{~mm}$ diameter; approximately 1.6 times more evenly than the granules with $6 \mathrm{~mm}$ diameter.

The analysis of the test results shows that uniformity is influenced by the discharge flow rate and the diameter of the fertilizer particles. This means that when the discharge flow rate was $200 \mathrm{~g} \mathrm{~s}^{-1}$, a more uniform distribution of particles with a diameter of $4 \mathrm{~mm}$ was observed. Meanwhile, when the discharge flow rate was $400 \mathrm{~g} \mathrm{~s}^{-1}, 6 \mathrm{~mm}$ diameter granular organic particles of poultry manure were more evenly distributed.

It can be observed that the number of fertilizer granules increases with the increasing flow through the discharge openings (shutter slides) of the fertilizer spreader (Figure 10a,b). The number of granules increases until a distance of $11.82 \mathrm{~m}$ is reached. The higher application rate of the fertilizer is reached at a distance of 11 to $14 \mathrm{~m}$. When this distance becomes greater than $14 \mathrm{~m}$, the number of granules begins to decrease significantly. The degree of distribution of fertilizer granules varies according to the Gaussian principle. The test results show that the effective working width has a slight upward trend, although the differences are not significant. Similar results of fertilizer spreading modeling were obtained by other researchers [23].

It can be concluded that it is possible to develop a model for spreading granular cylindrical organic fertilizer particles, and to perform the simulation in an EDEM software environment. 


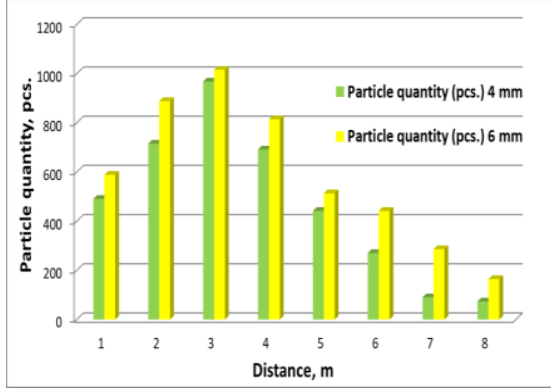

(a)

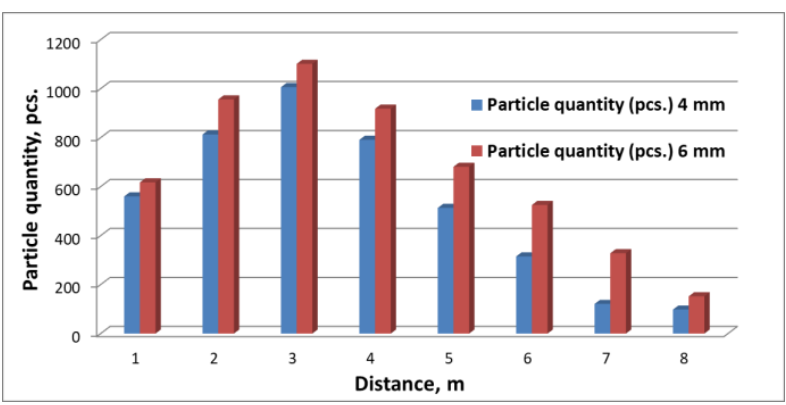

(b)

Figure 10. Spreading of fertilizer granules obtained at a disc rotation speed of $600 \mathrm{~min}^{-1}$ : (a) normal discharge flow rate of $200 \mathrm{~g} \mathrm{~s}^{-1}$; (b) normal discharge flow rate of $400 \mathrm{~g} \mathrm{~s}^{-1}$.

\section{Conclusions}

The results of this research show the following:

- A model can be developed for spreading granular cylindrical organic fertilizer particles;

- The simulation using the above model can be performed in an EDEM software environment;

- The distance traveled by a cylindrical granule of organic fertilizer depends on the physical-mechanical parameters, spread rate and spreader disc rotation speed.

The analysis of the simulation results shows that when the discharge flow rate was $200 \mathrm{~g} \mathrm{~s}^{-1}$, a more uniform distribution of particles with a diameter of $4 \mathrm{~mm}$ was observed. When the discharge flow rate was $400 \mathrm{~g} \mathrm{~s}^{-1}, 6 \mathrm{~mm}$ diameter granular organic particles of poultry manure were more evenly distributed. Moreover, the developed simulation model is a potential tool for the design and optimization of fertilizer spreaders. In fact, it could reduce the number of prototypes to be manufactured before it can be sold, and the number of tests to be performed for setting up the parameters of the machine.

Furthermore, the developed simulation model could provide information on the design of the setting-up and control systems mounted on centrifugal fertilizer spreaders. In fact, these systems are needed to perform spatially variable rate fertilizer application, within a precision agriculture cycle, meeting the needs of modern farmers and also environmentalists. Setting-up and control systems are now available for spatially variable rate fertilizer application. However, the systems on the market are expensive, and are often only compatible with devices produced by the same manufacturer.

Author Contributions: Conceptualization, R.Z., E.J., A.J., E.V. and A.C.; methodology, R.Z., E.J., A.J. and A.C.; software, R.Z., E.J. and A.J.; validation, R.Z., E.J. and A.J.; formal analysis, R.Z., E.J., A.J. and E.V.; investigation, R.Z., E.J. and A.J.; resources, R.Z., E.J. and A.J.; data curation, R.Z., E.J. and A.J.; writing-original draft preparation, R.Z., E.J., A.J. and A.C.; writing-review and editing, R.Z., E.J., A.J., A.C. and E.V.; visualization, R.Z., E.J., A.J., E.V. and A.C.; supervision, E.J.; project administration, R.Z., E.J. and A.J.; funding acquisition, R.Z., E.J. and A.J. All authors have read and agreed to the published version of the manuscript.

Funding: This research received no external funding.

Institutional Review Board Statement: Not applicable.

Informed Consent Statement: Not applicable.

Data Availability Statement: Not applicable.

Acknowledgments: The authors would like to thank the Institute of Agricultural Engineering and Safety of Agriculture Academy of Vytautas Magnus University for the test development and support.

Conflicts of Interest: The authors declare no conflict of interest. 


\section{References}

1. Foged, H.L.; Flotats, X.; Bonmati, A.; Palatsi, J.; Magri, A.; Schelde, K.M. Inventory of Manure Processing Activities in Europe. In Technical Report No.1 to the European Commission, Directorate-General Environment Concerning "Manure Processing Activities in Europe"; Project Reference: ENV.B.1/ETU/2010/0007; Agro Business Park: Tjele, Denmark, 2012; pp. 1-138.

2. Bond, W.; Grundy, A.C. Non-chemical weed management in organic farming systems. Weed Res. 2001, 41, 383-405. [CrossRef]

3. Jasinskas, A.; Pekarskas, J.; Kucinskas, V.; Aboltins, A. Investigation of natural magnesium mineral fertilizer granulation and determination of granule qualitative indicators. In Engineering for Rural Development 2016, Proceedings of the 15th International Scientific Conference Proceedings, Jelgava, Latvia, 25-27 May 2016; ASU Publishing Center: Akaemija, Lithuania, 2016; pp. 647-652.

4. Bhattacharya, S.C.; Sett, S.; Shrestha, R.M. State of the art for biomass densification. Energy Sources 1989, 11, 161-182. [CrossRef]

5. Sulky Product List. Available online: http://www.sulky-burel.com/products (accessed on 15 February 2020).

6. Dintwa, E.; Van Liedekerke, P.; Olieslagers, R.; Tijskens, E.; Ramon, H. Model for simulation of particle flow on a centrifugal fertilizer spreader. Biosyst. Eng. 2004, 87, 407-415. [CrossRef]

7. Carrara, M.; Comparetti, A.; Febo, P.; Orlando, S. A system for spatially variable rate fertilizer application. In Proceedings of the AgEng2004, International Conference on Agricultural Engineering, Leuven, Belgium, 12-16 September 2004; pp. 1-5.

8. Carrara, M.; Comparetti, A.; Febo, P.; Orlando, S. Adjustment time and offset of a system for spatially variable rate fertilisation. In Proceedings of the 5th European Conference on Precision Agriculture (5ECPA), Uppsala, Sweden, 9-12 June 2005; pp. 1-8.

9. Comparetti, A. Precision Agriculture: Past, Present and Future. In Agroinzinerija ir Energetika Nr. 16-2011, Proceedings of the International Scientific Conference "Agricultural Engineering and Environment-2011", Key-Note Presentation, Akademija, Kaunas District, Lithuania, 22-23 September 2011; ASU Publishing Center: Akaemija, Lithuania, 2011; pp. 216-230.

10. Sgaard, H.T.; Kierkegaard, P. Yield reduction resulting from uneven fertilizer distribution. Tran. ASAE 1994, 37, 1749-1752. [CrossRef]

11. Pocius, A.; Jotautienè, E.; Pekarskas, J.; Mieldažys, R.; Jasinskas, A. Research of particle geometrical parameters and aerodynamic features of granular organic compost fertilizers. In Engineering for Rural Development, Proceedings of the 13th International Scientific Conference Proceedings, Jelgava, Latvia, 29-30 May 2014; Latvia University of Agriculture: Jelgva, Latvia, 2014; pp. 401-406. Available online: http://tf.1lu.lv/conference/proceedings2014/Papers /68_Pocius_A2.pdf (accessed on 10 June 2020).

12. Olieslagers, R. Fertilizer Distribution Modelling for Centrifugal Spreader Design. Ph.D. Thesis, Nr. 341, Aan de Faculteit Derla Ndbouwwetenschappen, K.U., Leuven, Belgium, 1997.

13. Olieslagers, R.; Ramon, H.; De Baerdemaeker, J. Calculation of fertilizer distribution patterns from a spinning disc spreader by means of a simulation model. J. Agric. Eng. Resh. 1996, 63, 137-152. [CrossRef]

14. Hofstee, J.W.; Huisman, W. Handling and spreading of fertilizers part 1: Physical properties of fertilizer in relation to particle motion. J. Agric. Eng. Res. 1990, 47, 213-234. [CrossRef]

15. Liederkerke, P.V.; Piron, E.; Ramon, H.; Tijskens, E.; Vangeyte, J.; Villette, S. Recent results of experimentation and DEM modeling of centrifugal fertilizer spreading. Granul. Matter 2008, 10, 247-255. [CrossRef]

16. Bivainis, V.; Jotautienè, E.; Zinkevičienè, R.; Zokaitis, K. Investigation of geometrical particle parameters and aerodynamic features of granular manure fertilizers. In Engineering for Rural Development, Proceedings of the 16th International Scientific Conference Proceedings, Jelgava, Latvia, 24-26 May 2017; Latvia University of Agriculture: Jelgva, Latvia, 2017; pp. 1452-1457.

17. Mieldažys, R.; Jotautienè, E.; Jasinskas, A.; Pekarskas, J.; Zinkevičienè, R. Investigation of physical-mechanical properties and impact on soil of granulated manure compost fertilizers. J. Environ. Eng. Landsc. Manag. 2019, 27, 153-162. [CrossRef]

18. Yinyan, S.; Man, C.; Xiaochan, W.; Odhiambo, M.O.; Weimin, D. Numerical simulation of spreading performance and distribution pattern of centrifugal variable-rate fertilizer applicator based on DEM software. Comput. Electron. Agric. 2018, 144, 249-259. [CrossRef]

19. Amazone Ltd Web Page. Available online: https://amazone.net/en (accessed on 19 July 2019).

20. Rioual, F.; Piron, E.; Tijskens, E. Rolling and sliding dynamics in centrifugal spreading. Appl. Phys. Lett. 2007, 90, 021918. [CrossRef]

21. DEM Solutions Ltd. EDEM 2.6 Theory Reference Guide; DEM Solutions Ltd.: Edinurgh, UK, 2014.

22. Ai, J.; Chen, J.F.; Rotter, J.M.; Ooi, J.Y. Assessment of rolling resistance models in discrete element simulations. Powder Technol. 2011, 206, 269-282. [CrossRef]

23. Koko, J.; Virin, T. Optimization of a fertilizer spreading process. Math. Comput. Simulat. 2009, 79, 3099-3109. [CrossRef] 